\title{
SISTEMA DE PROTEÇÃO CONTRA INCÊNDIO E PÂNICO PARA EDIFICAÇÃO MULTIFAMI- LIAR
}

Thales Bastos de Souza

Graduando em Engenharia Civil, Unisuam, Rio de Janeiro, RJ, Brasil.

thales.bastos.s@gmail.com

Bruna Dias Soares de Sousa

Graduando em Engenharia Civil, Unisuam, Rio de Janeiro, RJ, Brasil.

bruna.dss@hotmail.com

Luiz Eduardo Amancio Aguiar

Mestre em Engenharia Civil - UFF/RJ - Unisuam.

leduaguiar@unisuam.edu.br

\section{RESUMO}

No presente artigo é apresentado os dispositivos contra incêndio utilizados em edifícios com característica multifamiliar, esclarecendo suas exigências de aplicação quanto a característica física e finalidade do edifício em questão. Também sendo abordado casos de dispositivos prejudicados devido à falta de manutenção preventiva e corretiva. As informações foram coletadas com base principal no código vigente do estado do Rio de Janeiro - COSCIP (Código de Segurança Contra Incêndio e Pânico) e nas normas complementares: Resoluções SEDEC (Secretaria de Estado de Defesa Civil). Bem como conhecimentos vivenciados na rotina de trabalho em uma empresa voltada a área de engenharia contra incêndio. No estudo de caso, é abordado informações relevantes sobre um determinado projeto de incêndio elaborado e tramitado junto ao CBMERJ no ano de 2017.

Palavras-chave: Dispositivos contra incêndio. Edificação multifamiliar. COSCIP. Projeto Contra Incêndio. Canalização preventiva. 
FIRE AND PANIC PROTECTION SYSTEM FOR MULTIFAMILIARY BUILDING

\begin{abstract}
In this article will be presented the devices against fire used in buildings with multifamily feature, clarifying their application requirements as to the physical characteristic and purpose of the building in question. Also being addressed cases of devices impaired due to lack of preventive and corrective maintenance. The information was collected based mainly on the current code of the state of Rio de Janeiro - COSCIP (Fire and Panic Safety Code) and the complementary norms: Resolutions SEDEC (Secretary of State for Civil Defense). As well as experienced knowledge in the routine work in a company focused on the area of fire engineering. In this case study, relevant information about a particular fire project prepared and processed with CBMERJ in the year 2017 will be approached.
\end{abstract}

Keywords: Fire-fighting devices. Multi-family building. COSCIP. Project Against Fire. Preventive channeling.

\title{
1 INTRODUÇÃO
}

A segurança contra incêndio tem sido foco de preocupação cada vez mais intensa em nosso País. Ainda que com a modernização tecnológica ao longo do tempo e o avanço na fiscalização, nas últimos décadas é possível recordar graves casos de incêndios que geraram elevados números de vítimas fatais, desses casos podem-se citar: Espetáculo GranCircus Norte-Americano (RJ) em 1961 com 503 mortes sendo 70\% crianças, Edifício Andraus (SP) em 1972 com 16 mortes, Edifício Joelma (SP) em 1974com 191 mortes, Lojas Renner (RS) em 1976 com 41 mortes, Edifício Andorinha (RJ) em 1986 com 21 mortes, Edifício Grande Avenida (SP) em 1981 com 17 mortes, Creche Uruguaiana (RS) em 2000 com a morte de 12 crianças, Canecão Mineiro em 2001 com 7 mortes e Boate Kiss em 2013 com 239 mortes. Em boa parte desses eventos foram verificadas falhas do sistemas contra incêndio ou até sua inexistência. Além desses trágicos casos de mortes em massa, é verificado perdas materiais/econômicas em grande escala.

A principal causa de óbitos em incêndios é devido a exposição à fumaça toxi- 
ca que ocorre durante a queima dos variados materiais que se encontram no interior dos estabelecimentos. Assim, é de total importância a segurança das pessoas que se encontram em um edifício, em que nele deverá existir saídas de emergências bem sinalizadas e dimensionadas, como também dispositivos de proteção que possibilite o combate ao foco de incêndio de forma emergencial. Ainda assim, mesmo que não haja a obrigatoriedade de sistemas mais complexos contra incêndio, a proteção deverá ser feita através de aparelhos extintores, iluminação de emergência, placas de sinalização, escadas e saídas emergenciais. E para determinados edifícios que estejam enquadrados em fator de maior atenção, são exigidos sistemas mais complexos, como: sistema de chuveiros automáticos, canalização preventiva com caixas de hidrantes, reserva técnica de incêndio, sistema de pressurização de escada, portas corta fogo, sistema de detecção e alarme, entre outros.

Esse trabalho tem como objetivo apresentar os dispositivos contra incêndio que são utilizados em edifícios de característica multifamiliar (pequeno risco), detalhando sua funcionalidade, modos de acionamentos e sua integração com todo o sistema preventivo contra incêndio e comparar aos casos de falta de manutenção. Também explicar o processo de elaboração do Projeto Contra Incêndio e seus passos quanto a tramitação junto ao Corpo de Bombeiro.

\section{DESENVOLVIMENTO}

\subsection{Enquadramento de risco}

As edificações segundo a regulamentação proposta pelo Corpo de Bombeiros do estado do Rio de Janeiro e contida no Art. 9 ○ do COSCIP, são divididas em 10 diferentes grupos:

1 - Residencial (privativa, coletiva ou transitória); 2 - Comercial; 3 - Industrial; 4 - Mista; 5 - Pública; 6 - Escolar; 7 - Hospitalar e laboratorial; 8 - Garagem; 9 - De reunião de público; 10 - De usos especiais diversos.

As divisões acima contribuem na avaliação quanto a exigência de qual 
sistema de proteção contra incêndio será instalada no estabelecimento.

No presente trabalho é abordado informações com foco à edificação residencial privativa multifamiliar (edifícios com 3 ou mais pavimentos). É importante esclarecer as subdivisões das edificações residenciais:

- Privativa: unifamiliar e multifamiliar.

- Coletiva: pensionatos, asilos, internatos e congêneres.

- Transitórias - hotéis, motéis e congêneres.

Para que seja avaliado o tipo de dispositivo de sistema contra incêndio a ser instalado no estabelecimento, o enquadramento quanto ao risco é o parâmetro primordial a ser avaliado. Na Resolução SEDEC 109/93 apresenta as 3 divisões:

- Edificações de pequeno risco;

- Edificações de médio risco;

- Edificações de grande risco.

As de pequeno risco, que é o foco do presente trabalho, engloba basicamente edificações unifamiliares e multifamiliares e mistas. Sendo esta última, com um único pavimento comercial, caso passe para dois ou mais pavimentos comerciais, torna-se de médio risco. As de médio risco compõem por: hotel, hospital, biblioteca, shopping, estabelecimentos comerciais, mercados, etc. As de grande risco basicamente englobam grandes fábricas que utilizam materiais inflamáveis (madeira, espuma, tecido, papelão, cera, óleos combustíveis, etc).

\subsection{Dispositivo preventivo contra incêndio}

Os dispositivos preventivos contra incêndio são sistemas instalados internamente ou perifericamente à estrutura da edificação e possui seu funcionamento de forma automática (ex: sistema sprinkler) que são interligados através de tubulação de ferro galvanizado ou aço carbono ou de uso manual (ex: 
mangueira de incêndio). São acionados por um sistema automatizado de eletrobombas, que se encontram no interior da casa de máquinas de incêndio (CMI) ou "abrigos", geralmente localizada nos últimos pavimentos do edifício (alguns casos situada no térreo ou subsolo). Esses dispositivos têm como finalidade o combate ao princípio de incêndio que compreenda o prisma do estabelecimento. Os tipos de dispositivos são exigidos quanto ao grau de risco que a edificação se enquadra, segundo fatores de área construída, altura total do edifício. Essas exigências estão formalizadas no COSCIP e nas Resoluções SEDEC.

Para as edificações residências privativas multifamiliares, existe um enquadramento quanto aos números de pavimentos, altura total e área construída, conforme apresenta a tabela 1.

Tabela 1 - Relação da característica do edifício e a exigência de dispositivos

\begin{tabular}{|c|c|c|c|l|}
\hline \multicolumn{2}{|c|}{ Até 3 pavimentos } & $\begin{array}{l}\text { A partir de 4 pavi- } \\
\text { mentos e até 30m } \\
\text { de altura }\end{array}$ & Acima de 30m de altura \\
\cline { 2 - 6 } Área construída & $<900 \mathrm{~m}^{2}$ & $>900 \mathrm{~m}^{2}$ & \multicolumn{1}{|c|}{------} & \multicolumn{1}{c|}{----- } \\
Exigência & $\begin{array}{c}\text { Isenta de insta- } \\
\text { lação fixa }\end{array}$ & $\begin{array}{l}\text { - Canalização } \\
\text { preventiva }\end{array}$ & $\begin{array}{l}\text { - Canalização pre- } \\
\text { ventiva } \\
\text { - Porta corta fogo }\end{array}$ & $\begin{array}{l}\text { tiva } \\
\text { - Porta corta fogo } \\
\text { - Chuveiros automá- } \\
\text { ticos }\end{array}$ \\
\hline
\end{tabular}

Fonte: (Extrato - COSCIP, 1976)

Para os edifícios que necessitem do sistema de canalização preventiva é exigido reservatório d'agua inferior e outro superior. Em que a reserva técnica do reservatório superior deverá se enquadrar da forma que: 
Tabela 2 - Relação caixa de hidrantes e reserva técnica

\begin{tabular}{|l|l|}
\hline - Edificações com até 4 (quatro) caixa de hidrantes: & 6.000 I (seis mil litros) de reserva técnica. \\
\hline - Edificação com mais de 4 (quatro) caixa de hidrantes: & $\begin{array}{l}6.000 \text { I (seis mil litros), acrescido de } 500 \text { I (qui- } \\
\text { nhentos litros) por cada hidrante excedente. }\end{array}$ \\
\hline
\end{tabular}

Fonte: (Extrato - COSCIP, 1976)

\subsection{Canalização preventiva}

A canalização preventiva inicia na tubulação que sai da parte de baixo do reservatório, entra no barrilete de incêndio, passa pela válvula de retenção e do registro, passa pelo sistema de pressurização (quando existente) e desce para os pavimentos. Isso para casos em que a $\mathrm{CMI}$ seja executada nos últimos pavimentos.

Na figura 1 pode-se observar o sistema de incêndio de um prédio de forma simplista, apresentando desde o reservatório superior do prédio com sua reserva técnica, sistema de eletrobombas, a tubulação de incêndio que passa por todos os andares sendo ramificado para as caixas de incêndio de cada pavimento, terminando no hidrante de recalque (hidrante de passeio), fora do prisma da edificação.

Figura 1 - Corte da edificação com sistema preventivo contra incêndio

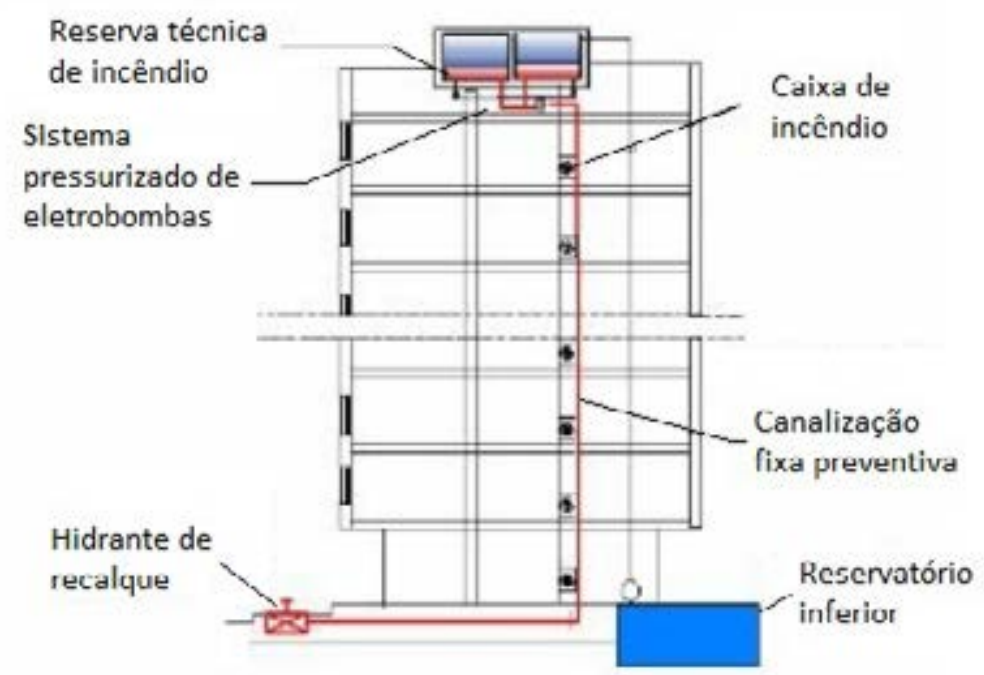


Fonte: (Editado - Apostila Bombeiro Profissional Civil, CBMES. 2009)

Como já foi dito, há casos onde a saída da tubulação preventiva de incêndio inicia no reservatório inferior e é pressurizada de forma que o água chegue até o último dispositivo contra incêndio instalado.

A canalização preventiva deve resistir a uma pressão de $18 \mathrm{~kg} / \mathrm{cm}^{2}$ e com diâmetro mínimo de 2.1/2" (Art. 26ㅇ - COSCIP, 1976). E deverão estar pintadas de vermelho quando forem visíveis. O sistema de canalização tem seu controle de pressurização devido ação do tanque de pressão que se encontra na Casa de Máquinas de Incêndio (CMI) e interligado a um manômetro que afere constantemente a pressão interna na tubulação. $\mathrm{Na}$ CMI (figura 2) também se encontram elementos fundamentais ao funcionamento correto do sistema de canalização preventiva, sendo compreendido basicamente de: eletrobomba, pressostato, manômetro, painel de comando, tanque de pressão, além das conexões e registros.

Ao ser aberto manualmente um registro para uma mangueira de incêndio, a pressão interna da canalização de incêndio diminui e essa queda de pressão é aferida pelo manômetro e transmitida ao painel elétrico. Com isso, o painel elétrico aciona o sistema de eletrobomba de forma automática, mantendo a vazão de água enviada para a mangueira de forma constante, para o combate efetivo ao sinistro.

Vale ressaltar que edificações anteriores à 21/09/1972 (data em que o COSCIP foi promulgado), após avaliação, podem se eximir de algumas exigência, como por exemplo manter a tubulação das caixas de hidrantes com diâmetro de 2" ou também de não ser necessário se adequar à inserção do sistema de chuveiros automáticos. 
Figura 2 - Componentes básicos de uma CMI

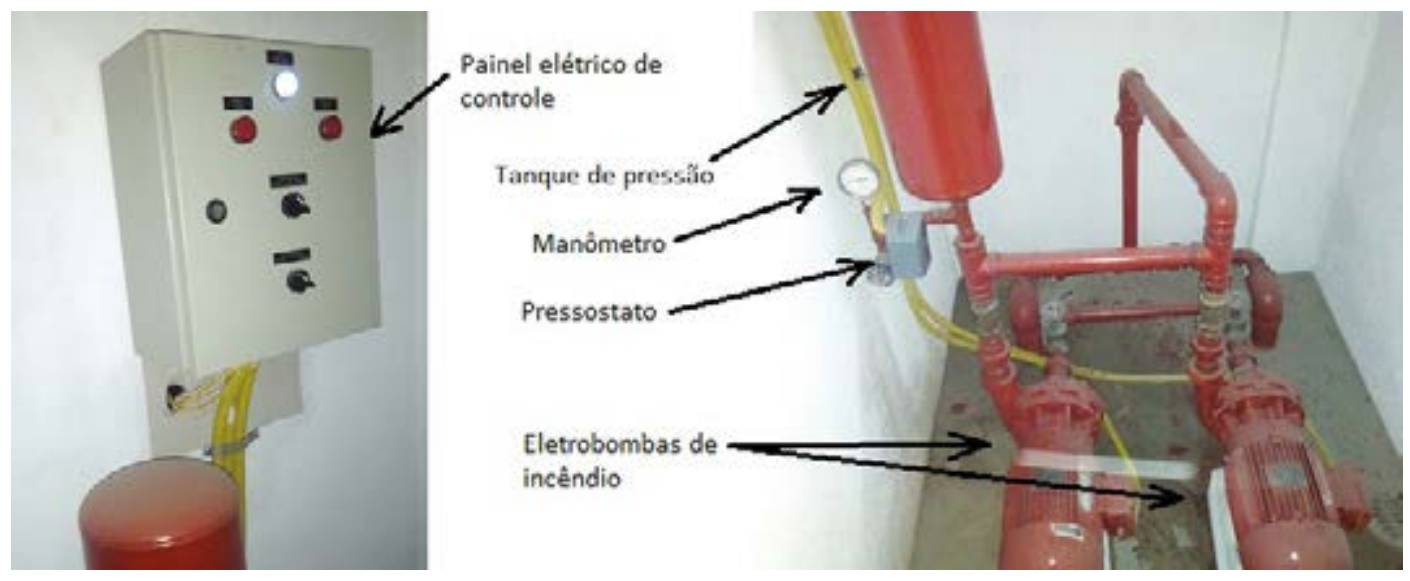

Fonte: (Autor, 2017)

2.4 Dispositivo preventivo fixo

Os dispositivos preventivos fixo serão detalhados nas páginas seguintes desse trabalho com o intuito esclarecer pontos importantes de sua forma de funcionamento, exigências de aplicação, como também comparações com dispositivos de manutenção precária ou maneiras incorretas de instalação.

\section{Caixa de incêndio}

Também pode ser chamada de "abrigo de incêndio", geralmente mencionada dessa forma para as de maiores dimensões. As caixas de incêndio tem dimensões mínimas de $70 \mathrm{~cm}$ de altura, $50 \mathrm{~cm}$ de largura e $25 \mathrm{~cm}$ de profundidade. E contendo os seguintes elementos: registro globo, juntas storz, mangueiras e o esguicho (figura 3). Para edificação multifamiliarde baixo risco, é exigido o esguicho tradicional, de agulheta (de requinte). E dependendo da distância máxima ao local a ser coberto pela caixa de incêndio, possuirá até 2 seguimentos de mangueiras, cada mangueira com tamanho de $15 \mathrm{~m}$.

As caixas de incêndio devem estar localizadas em local de fácil acesso de forma 
que nenhum objeto esteja impedindo o seu uso em caso de emergência. Devem estar com molduras pintadas de vermelho e com adesivo informativo de "INCÊNDIO". A pressão d’água exigida em qualquer dos hidrantes será, no mínimo, de $1 \mathrm{~kg} / \mathrm{cm} 2$ (um quilo por centímetro quadrado), e, no máximo, de $4 \mathrm{~kg} / \mathrm{cm} 2$ (quatro quilos por centímetro quadrado). (Art 27. COSCIP, 2003).

Figura 3 - Caixa de incêndio
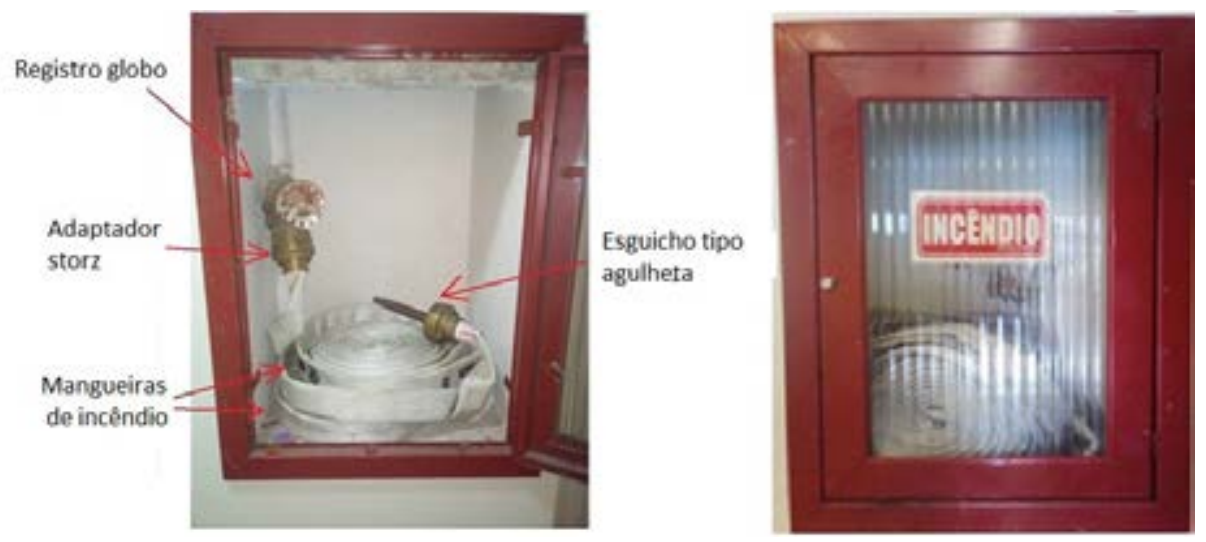

Fonte: (Autor, 2017)

Em locais que não são realizados a manutenção preventiva, podem-se apresentar estados de vazamento e oxidação, sendo facilmente visíveis no interior das caixas de incêndio, como é demonstrado na figura 4 e 5 . Acarretando em um desgaste acelerado do material, sendo necessário seu reparo ou troca. Bem como pode chegar ao ponto de danificar o revestimento e a alvenaria do edifício, gerando custos elevados para esses reparos que poderiam ser evitado. 
Figura 4 - Caixa de incêndio com vazamento/oxidação deteriorada

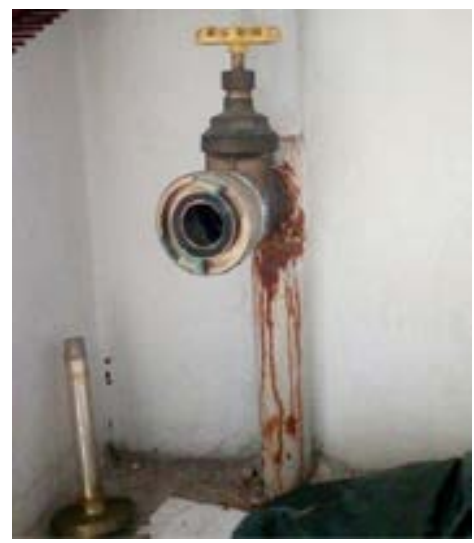

Fonte: (Autor, 2017)
Figura 5 - Caixa de incêndio

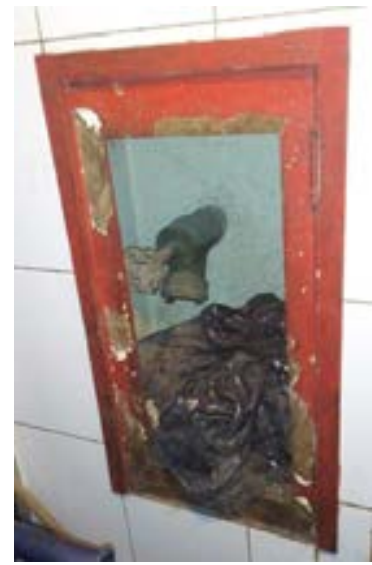

Fonte: (Autor, 2017)

Para o presente caso de estudo, edifício caracterizado em "risco pequeno", as mangueiras são de 1.1/2". Também existem as de 2.1/2" para risco grande. Ainda para o caso do presente trabalho, na saída de do hidrante, deve-se ter vazão mínima de 100l/min após seu acionamento e para os casos de "grande risco" a pressão mínima no hidrante será de $400 \mathrm{kPa}$. Essas informações são levantadas através de cálculos hidráulicos durante o processo de elaboração de Projeto Contra Incêndio.

\section{Hidrante de recalque}

Também pode ser chamado de hidrante de passeio, é localizado na parte externa da edificação para o uso do combate ao incêndio pelo Corpo de Bombeiros. É composto por um registro de gaveta, junta "storz" e um tampão de material metálico com dimensão de $40 \mathrm{~cm}$ x $30 \mathrm{~cm}$, com o aviso de "INCÊNDIO" (figura 6). 
Figura 6 - Hidrantes de recalque
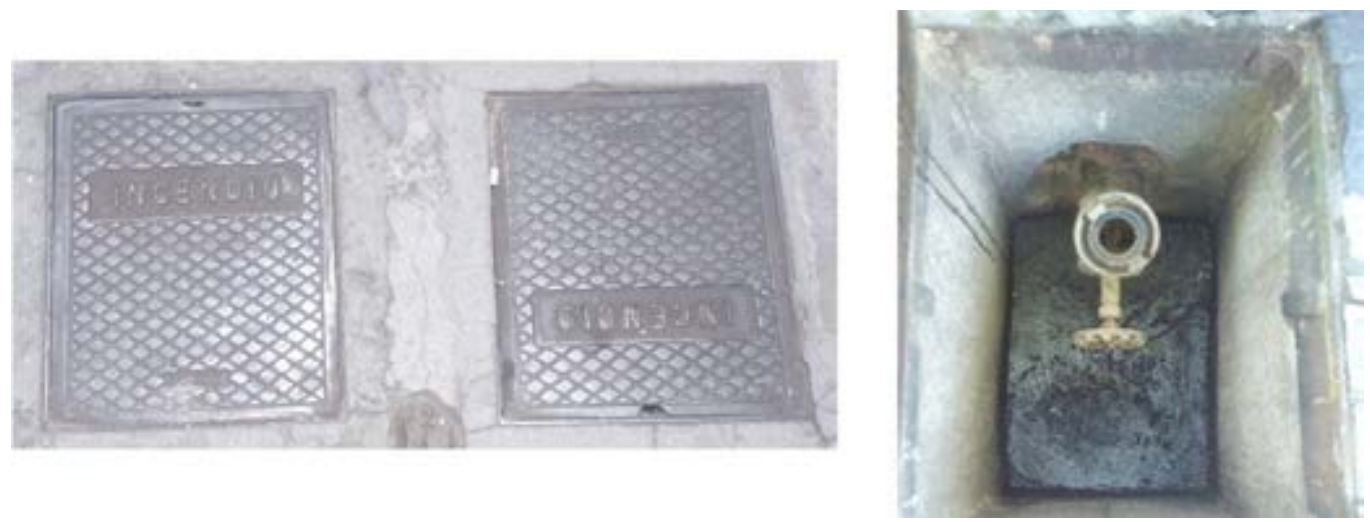

Fonte: (Autor, 2017)

Nos casos em que exista o sistema fixo de canalização de incêndio é exigido a instalação do hidrante de recalque. A quantidade de hidrantes de recalque é estipulada pela distância máxima de $30 \mathrm{~m}$ da caixa para o ponto mais distante a ser protegido por ela (Art. 30으 - COSCIP, 1976). Assim sendo necessário a instalação de mais de uma caixa de hidrante de recalque dependendo das dimensões do edifício. Nos locais onde também é aplicado o sistema de chuveiros automáticos (sprinklers) existirá mais um hidrante de recalque, assim sendo um referente a tubulação das caixas de incêndio que desce pelo edifício até o recalque e outro hidrante de recalque que vem da canalização da rede de sprinklers. Geralmente esses dois hidrantes de recalque se localizam um próximo ao outro.

O hidrante de recalque é utilizado de forma que o Corpo de Bombeiro possa injetar um fluxo de água para o interior do sistema do prédio de forma a manter a entrada de água para o uso das caixas de hidrante e dos chuveiros automáticos, como também pode ser utilizado para retirada de água do sistema do prédio vizinho para seu uso ao combate do incêndio no prédio afetado.

O hidrante de recalque é o dispositivo mais afetado pelo descaso quanto a sua manutenção. Além de não estar tão acessível às pessoas, o seguimento de tubulação que antecede e o dispositivo é geralmente enterrado. Tendem a se desgastar mais rapidamente devido as intempéries, da ação da umidade e contato com solo, caso não envelopado com concreto ou manta asfáltica. Também 
pode ser recorrente vazamentos nas conexões (união, joelho) e nos registro devido a carga de água sobre esses elementos. Na figura 7 pode-se evidenciar dois exemplos de deterioração do dispositivo, tornando-os inutilizáveis.

Figura 7 - Hidrantes de recalque deteriorados
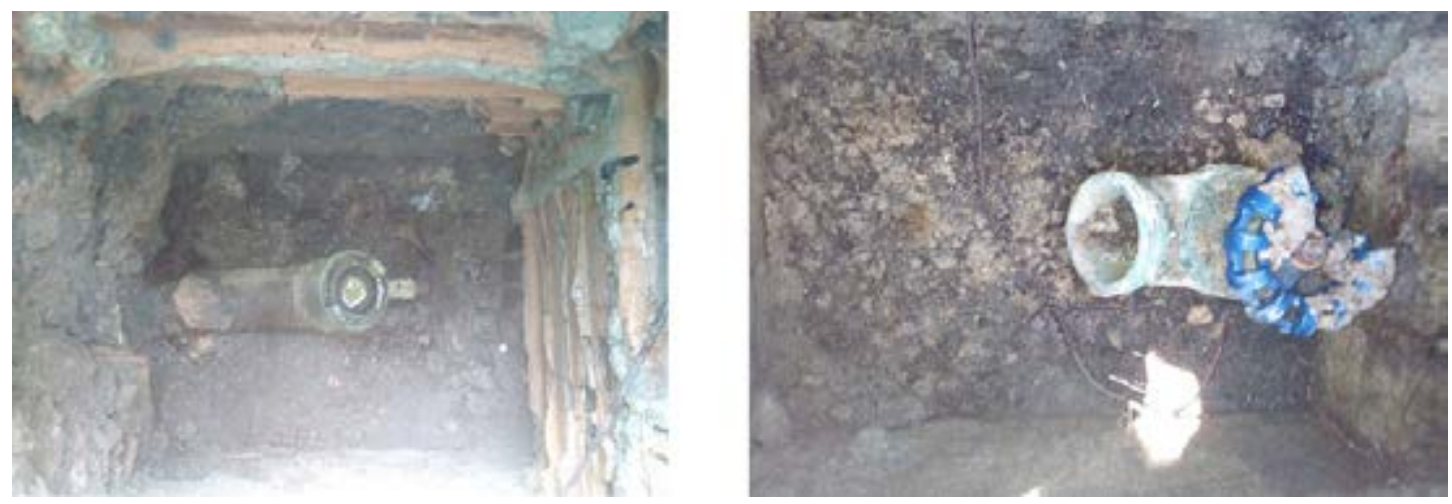

Fonte: (Autor, 2017)

\section{Chuveiro automático}

O chuveiro automático também pode ser chamado de "sprinkler". No enfoque do presente trabalho: edificação residencial privativa multifamiliar; a exigência para a instalação do sistema é para edificações acima de $30 \mathrm{~m}$ do nível do logradouro público (art. 80, cosCIP). E o nível do risco é considerado como "edificações de pequeno risco". Fator que será considerado para dimensionar, como exemplo, a área de atuação de cada bico, geralmente cobrindo cerca de $18 \mathrm{~m}^{2}$ de uma área circular.

Os bicos de saída deverão são instalados em locais cobertos e de uso comum aos pavimentos, nos subsolos e nas áreas de estacionamento. $\mathrm{O}$ bico é composto por um bulbo de vidro sensível ao calor, contendo a substancia "álcool" em seu interior, esse podendo variar a temperatura de sua ebulição, servindo para cada tipo de riscos e sua respectiva exigência. As cores diferenciadas do bulbo informam a temperatura limite do ambiente para o seu acionamento. $O$ mais utilizado em edifícios residenciais são os de bulbos vermelhos, com temperatura de acionamento em 68 graus. Ao alcançar a temperatura limite, o vidro do bulbo se rompe e tem-se a despressurização do sistema, assim 
entrando em ação o sistema automatizado de eletrobomba, dando início a descarga de água saindo pelo bico e atingindo a área afetada.

Figura 8 - Sistema de canalização de chuveiros automáticos

Figura 9 - Bico sprinkler acionado

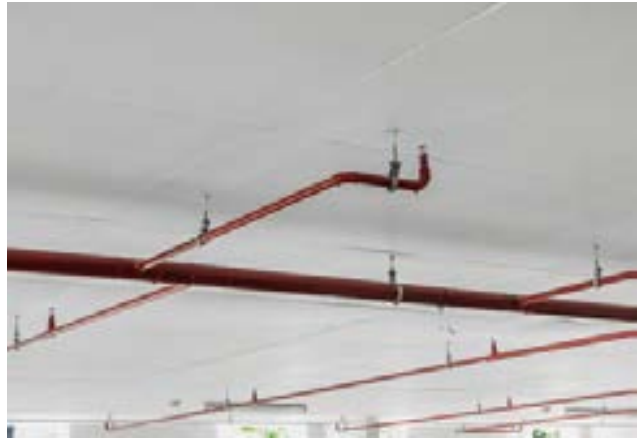

Fonte: (Excomer)

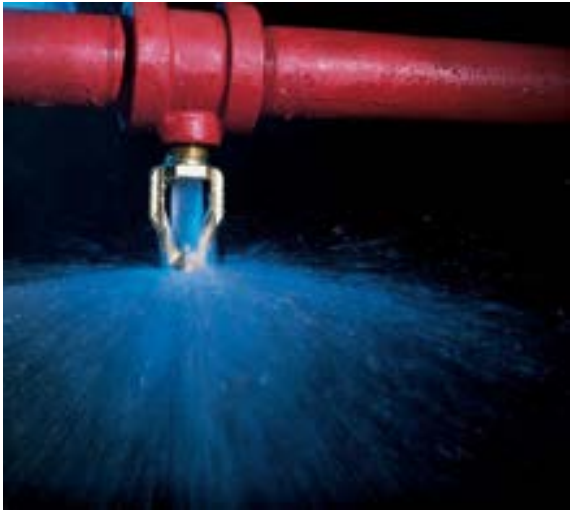

Fonte: (Hidrovar, 2016)

Nas ocupações de risco leve, para efeito de dimensionamento, a área de cobertura por bico não deve exceder a $18,6 \mathrm{~m}^{2}$, utilizando os cálculos por tabela e $20,9 \mathrm{~m}^{2}$ utilizando a forma de cálculo hidráulico (NBR 10897). E quanto maior o risco do local, menor ficará esse limite de área de cobertura. Esse fator de área de cobertura poderá ser alterado dependendo do tipo de cálculo utilizado (por tabela ou hidraulicamente calculado). Também para o dimensionamento, os bicos podem ficar em uma distância máxima entre um e outro de até 4,6m. Sempre levando em conta que essas informações são relativas ao caso do presente trabalho: edifício residencial multifamiliar e enquadrado em pequeno riso. As informações que regem as regras de dimensionamento e instalação dos chuveiros automáticos se encontram inicialmente no COSCIP e se aprofundam na NBR 10897-14.

Quanto ao mal funcionamento desse dispositivo e sua dificuldade de aprovação quanto aos proprietários e usuários do local, muitas das vezes é devido as falhas de instalação. 
ocorrem por falhas na operação do sistema durante um incêndio e sim durante o período que a instalação está em repouso. Vazamentos, aberturas inesperadas de bicos de sprinkler, rompimento de tubulações e conexões, danos a manômetros e chaves de fluxo são alguns dos inconvenientes vividos por muitos proprietários deste tipo de instalação. (EMERGÊNCIA, 2017)

Com tudo, pode-se reafirmar a preocupação quanto a empresa que irá realizar a instalação. Se é cadastrada no Corpo de Bombeiros, verificar referências de outros serviços realizados por ela e se possível fazer o acompanhamento das etapas de instalação. Pois um vazamento nessa tubulação ou até mesmo o acionamento incorreto desses bicos, poderá causar grandes danos aos materiais que ali estejam, interdição do local prejudicado e muitas das vezes sendo necessária a reabertura do rebaixamento de teto para o devido conserto da canalização ou do bico mal instalado.

Para a reserva técnica em edificações de risco pequeno, a Resolução SEDEC 300, preconiza que ela deverá ser dimensionadas para atender um funcionamento ininterrupto de no mínimo 30 minutos. Já para as de risco grande, 60 minutos.

\section{Porta corta fogo}

As Portas Corta Fogo são utilizadas com o objetivo de bloquear o alastramento do incêndio para compartimentos estratégico, com a função de permitir a saída de forma emergencial das pessoas. São posicionadas nos acessos às escadas de emergência, em salões que concentrem grandes quantidades de pessoas, separações de áreas de risco e em quaisquer ambiente onde seja visto a importância do impedimento momentâneo do fogo em caso de sinistro.

A PCF é composta por chapas de aço em sua parte externa, pintadas com tinta anti chamas e internamente possui material isolante. Ela deve estar obrigatoriamente fechada, mas nunca trancada, através de mecanismo de mola hidráulica ou dobradiças helicoidais.

As PCFs são classificadas em 4 classes de resistências (tabela 3), determinando seu tempo de resistência quando submetida a ação do fogo: 
Tabela 3 - Classe x Resistência de PCFs ao fogo

\begin{tabular}{|c|c|}
\hline Classe & Resistência ao tempo \\
P-30 & $30 \mathrm{~min}$ \\
\hline P-60 & $60 \mathrm{~min}$ \\
\hline P-90 & $90 \mathrm{~min}$ \\
\hline P-120 & $120 \mathrm{~min}$ \\
\hline
\end{tabular}

Fonte: (Extrato - NBR-11742, 2003)

Algumas portas também tem a função de impedir a progressão da fumaça (causadora de maiores danos às pessoas em um incêndio), elas são identificadas com a letra "F" após a letra "P", assim, por exemplo: PF-60, porta corta fogo resistente ao fogo por 60 min e também à prova de fumaça.

As PCFs podem variar quanto ao número de suas folhas: porta corta fogo simples, para uma folha e porta corta fogo dupla, para duas folas. Essas, utilizadas em lugares em que seja necessário a passagem de grandes objetos ou lugares com grande concentração de público (NBR 11.742).

Em relação a disposição de sua abertura/fechamento:

\footnotetext{
As portas devem ser instaladas de modo que a abertura da(s) folha(s) se processe no sentido de evasão. Se necessário, podem abrir no sentido contrário ao da evasão, desde que o número de pessoas que tenham que utilizá-las, em caso de fuga, não seja superior a 50. Neste caso, a porta não deve intervir na rota de fuga. (NBR-11742, 2003)
}

Assim, sendo preferencialmente instalada, no caso do presente trabalho, com sua abertura no sentido do ambiente em comum para o local protegido (ex: do ambiente comum aos apartamentos para a escada de emergência).

Nas edificações multifamiliares as PCFs são instaladas nas entradas das escadas de emergência de todos os pavimentos, nos acessos a CMI, Casa de Máquinas de Elevador (CME) e no quadro geral elétrico do edifício.

Dentro das caixas de escada, acima da porta corta-fogo leve, haverá a indicação, em local bem visível, do número do pavimento correspondente (Art. 
183으 - COSCIP, 1976).

Figura 10 - Porta Corta Fogo

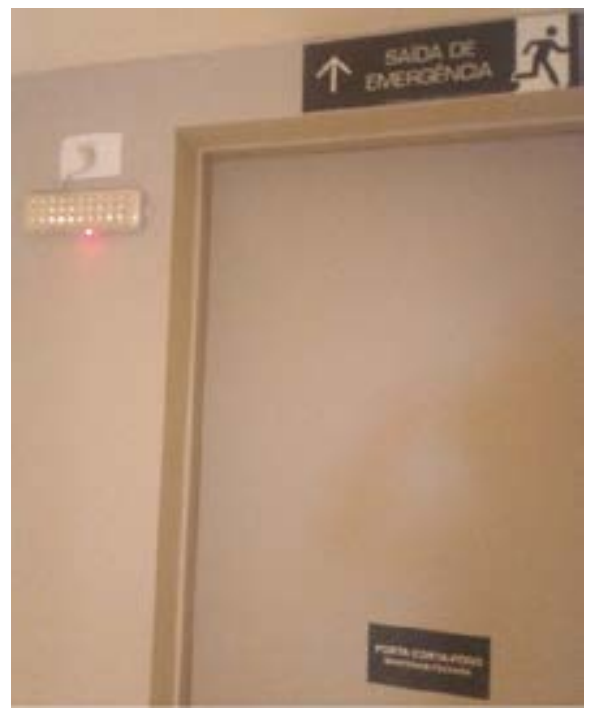

Fonte: (Autor, 2017)

Na figura 10 é possível verificar uma PCF acompanhada da correta instalação do sistema de sinalização e iluminação de emergência. Com a indicação de "PORTA CORTA FOGO" e em cima da porta a sinalização de "SAÍDA DE EMERGÊNCIA". Já as luminárias de emergência devem estar instaladas estrategicamente em locais de uso comum, no corredor, próximas às PCFs e em seguimentos das escadas de emergência.

2.5 Dispositivo preventivo móvel

Dentre os dispositivos contra incêndio, os extintores são os dispositivos mais comuns nos estabelecimentos. Os extintores portáteis fazem parte do sistema básico de segurança contra incêndio em edificações e devem ter como características principais: portabilidade, facilidade de uso, manejo e operação (ITIU, 2008). São exigidos ainda que haja outros dispositivos mais complexos instalados no local. Tem por finalidade o combate ao princípio de incêndio com seu uso de forma manual. E são separados em 4 classes distintas, cada uma determina o tipo de material a ser protegido (tabela 4). As classes D 
e K são tituladas como "classes especiais".

Tabela 4 - Classes extintores e materiais a ser protegido

\begin{tabular}{|l|l|}
\hline Classe A & Papelão, tecido, madeira, lixo e semelhantes. \\
\hline Classe B & Líquidos inflamáveis, graxa, plásticos, tinta e semelhantes. \\
\hline Classe C & Equipamentos energizados, quadro elétrico e semelhantes. \\
\hline Classe D & Materiais pirofóricos: magnésio, zinco, alumínio e outros. \\
\hline Classe K & Em cozinhas, queima de óleo e gorduras. \\
\hline
\end{tabular}

Fonte: (Extrato - Art. 25 - COSCIP, 1976)

Abaixo temos uma tabela que apresenta a área máxima protegida por unidade extintora e a distância máxima que poderá ficar do operador mais próximo. Lembrando que para o presente trabalho, que é abordado apenas edifícios residenciais multifamiliares, a categoria que se enquadra é risco leve (sendo ela sem a presença de cozinha industrial, lavanderia). Na tabela 5 pode-se verificar a área máxima a ser protegida por uma unidade extintora e sua distância máxima para o alcance do operador mais próximo.

Tabela 5 - Riscos $x$ área de proteção e distância máxima percorrida

\begin{tabular}{|c|c|c|}
\hline Risco & $\begin{array}{c}\text { Área máxima a ser protegida por } \\
\text { unidade extintora }\end{array}$ & $\begin{array}{c}\text { Distância máxima para o al- } \\
\text { cance do operador }\end{array}$ \\
\hline Leve & $200 \mathrm{~m}^{2}$ & $20 \mathrm{~m}$ \\
\hline Médio & $150 \mathrm{~m}^{2}$ & $15 \mathrm{~m}$ \\
\hline Grande & $100 \mathrm{~m}^{2}$ & 10 \\
\hline
\end{tabular}

Fonte: (Extrato - Art. 250 - COSCIP, 1976)

Os extintores deverão ser instalados de forma a que nenhum objeto impeça o seu uso em caso de emergência. Deverá ser instalado de forma que não ultrapasse a altura de $1,8 \mathrm{~m}$ de seu ponto mais distante do piso (COSCIP, 76) e com sinalização informando a classe do extintor (figura 11). E jamais poderá ser instalado nas escadas ou antecâmaras das escada. 
Figura 11 - Extintores e placas de sinalização

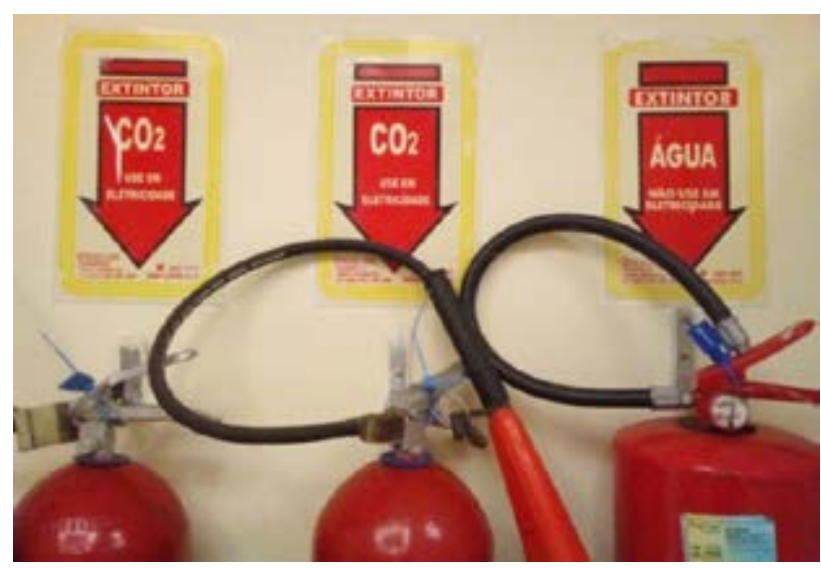

Fonte: (Autor, 2017)

A sinalização com placas informativas para os aparelhos extintores também é de obrigatoriedade, estando em local de fácil visibilidade e indicando qual classe a unidade extintora se enquadra e onde poderá ser aplicado. Sinalização de coluna deve aparecer em todo o seu contorno, recomendando-se utilização de setas, círculos ou faixas vermelhas com bordas amarelas, situados em nível superior aos extintores (NBR 12693).

\section{ESTUDO DE CASO}

A elaboração e tramitação do Projeto de Incêndio para determinados edifícios é de fundamental importância para a sua legalização e liberação por parte do Corpo de Bombeiro. Qualquer edificação que tenha 3 pavimentos (com área total maior que $900 \mathrm{~m}^{2}$ ) e/ou de 4 pavimentos em diante, deverão possuir canalização preventiva, e de forma subsequente, será necessário o projeto de incêndio conforme é estipulado no COSCIP e Resolução SEDEC 169-94.

Será apresentado ao longo desse estudo de caso um projeto de incêndio aprovado pelo Corpo de Bombeiro de um edifício multifamiliar de 2 blocos. O bloco 01 com 11 pavimentos e o bloco 02 com o total de 10 pavimentos, sendo o segundo possuindo 
subsolo usado como estacionamento. A edificação está situada na cidade do Rio de Janeiro.

O jogo de plantas a ser elaborado deve contar com: planta baixa de todos os pavimentos, situação, fachada, cortes e isométrico do sistema fixo. Contendo os dispositivos de incêndio demonstrados de forma clara no projeto. E deverá ser dado entrada no Corpo de Bombeiro por profissional habilitado e credenciado. O trâmite demora em torno de 30 dias para que se tenha o retorno com o deferimento ou indeferimento do projeto. Com a aprovação do projeto de incêndio, é fornecido pelo CBMERJ o Laudo de Exigências (LE), documento fornecido pelo Corpo de Bombeiro apresentando todos os dispositivos a serem instalados, informações de áreas, da empresa que realizou o projeto como também informações básicas do responsável pelo empreendimento. Com isso, é iniciado o prazo de 2 anos para que o edifício cumpra com a execução do projeto. Após cumprimento das exigências, é feito um novo requerimento solicitando a Vistoria de Aprovação. Sendo a vistoria feita por um profissional do Corpo de Bombeiros, e após o prazo de mais 40 dias (podendo ser prorrogado por mais tempo), recebe-se o Certificado de Aprovação (CA), para o caso de sua aprovação. 
Figura 12 - Prancha de situação, legendas e detalhes

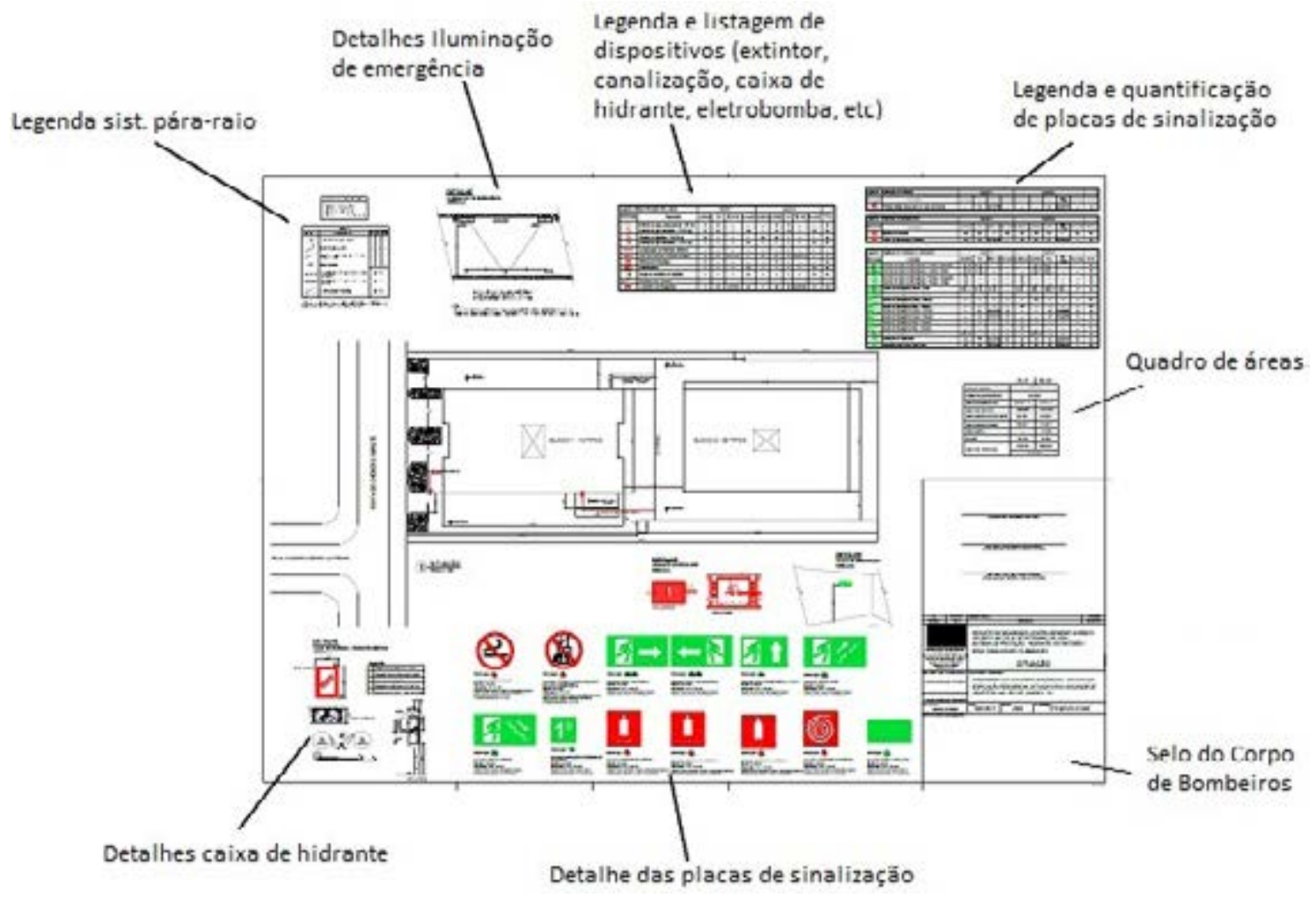

Fonte: (Projeto de Incêndio, 2017)

Como consta na figura 12 , nesse jogo de plantas a ser entregue, uma das pranchas irá demonstrar os detalhamentos, legendas, quantificação de materiais e das áreas de todo o condomínio.

Na figura 13, é apresentado a tabela de legenda do sistema preventiva fixo e o móvel dos dispositivos que se encontram em todo o condomínio, separados por pavimento e o bloco, assim como sua quantidade total. 
Figura 13 - Legenda Sistema Preventivo Fixo e Móvel

\begin{tabular}{|c|c|c|c|c|c|c|c|c|c|c|c|}
\hline \multicolumn{2}{|c|}{ Legenda - Sistema Preventivo Fixo e Movel } & \multicolumn{4}{|c|}{ BLOCO 1} & \multicolumn{5}{|c|}{$\mathrm{BLOCO} 2$} & \multirow[b]{2}{*}{ TOTAL } \\
\hline Simbologia & Descrição & ACESSO & Puc & nPO 10 & TELHADO & SUBSOLC & ACESSO & PUC & TIPO $\times 09$ & TEUHADO & \\
\hline (4) & Extuntor de água pressunzada - AI YUL & U1 & บ1 & - & - & - & 01 & U1 & - & - & 04 \\
\hline (9) & Extintor de gás carbónico - CO2 $6 \mathrm{~kg}$ & 01 & 01 & - & 02 & - & 01 & 01 & - & 02 & 08 \\
\hline$\theta$ & Extintor pó químico - PQS $6 \mathrm{~kg}$ & 02 & - & - & - & 04 & 03 & - & - & - & 09 \\
\hline (4) & 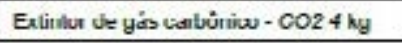 & - & - & - & 01 & - & - & - & - & 01 & 02 \\
\hline छब & $\begin{array}{l}\text { Canalizaçäo de Hidrantes } 050 \mathrm{~mm} \\
\text { Calxa de incendo (HIdrante Simples) }\end{array}$ & - & - & $\begin{array}{c}- \\
02 \times 10-20\end{array}$ & - & - & - & - & $\mid \begin{array}{c}- \\
02 \times 09-18\end{array}$ & - & - \\
\hline 圂 & Hidronte de Reaslque & 01 & - & - & - & - & 01 & - & - & - & 02 \\
\hline $1=0$ & Eletrobomba & - & - & - & 01 & - & - & - & - & 01 & 02 \\
\hline $\mathrm{CMI}$ & Abrigo de bombas de Incéndio & - & - & - & 01 & - & - & - & - & 01 & 02 \\
\hline 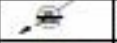 & Indiraģãn de Prumarla & - & - & - & - & - & - & - & - & - & - \\
\hline$\square$ & Luminária de Emergéncia & 11 & 06 & $4 \times 10=40$ & 02 & 11 & 06 & 06 & $04 \times 09-36$ & 02 & 120 \\
\hline
\end{tabular}

Fonte: (Projeto de Incêndio, 2017)

Na figura 14, imagem de uma região retirada da prancha do subsolo do bloco 02. São apresentados os locais onde deverão ser instalados as luminárias de emergência; as duas caixas de incêndio; os extintores com suas classes; as sinalizações de saída de emergência, da porta corta fogo, do pavimento; como também a indicação por onde a tubulação fixa passa. No presente caso a tubulação desce do pavimento superior e segue pelo teto até as duas caixas e termina no hidrante de recalque localizado entre o bloco 01 e o 02.

Figura 14 - Prancha do subsolo do bloco 02

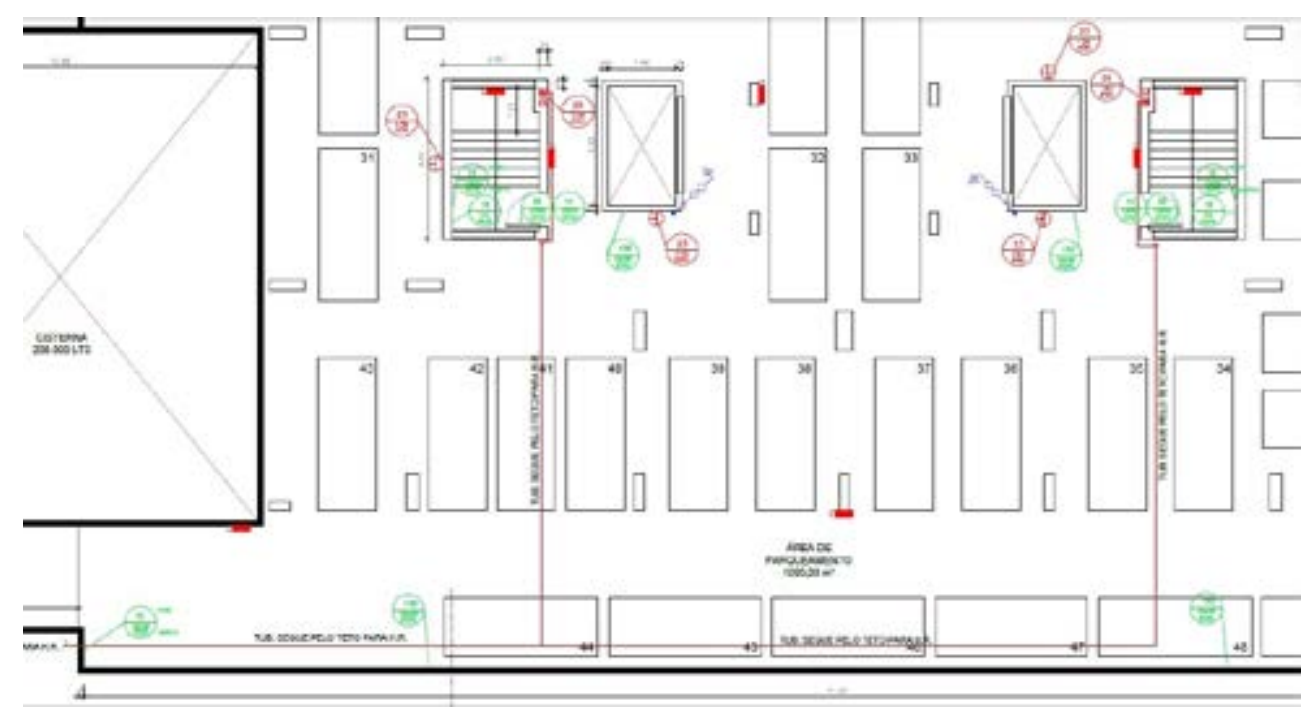


Fonte: (Projeto de Incêndio, 2017)

Como já foi dito, também é necessário a elaboração do projeto isométrico juntamente aos demais projetos, e serão apresentados para devida aprovação. Na figura 15 tem-se o projeto isométrico do bloco 01 do condomínio em questão.

Figura 15 - Sistema isométrico do sistema fixo de incêndio para o bloco 01

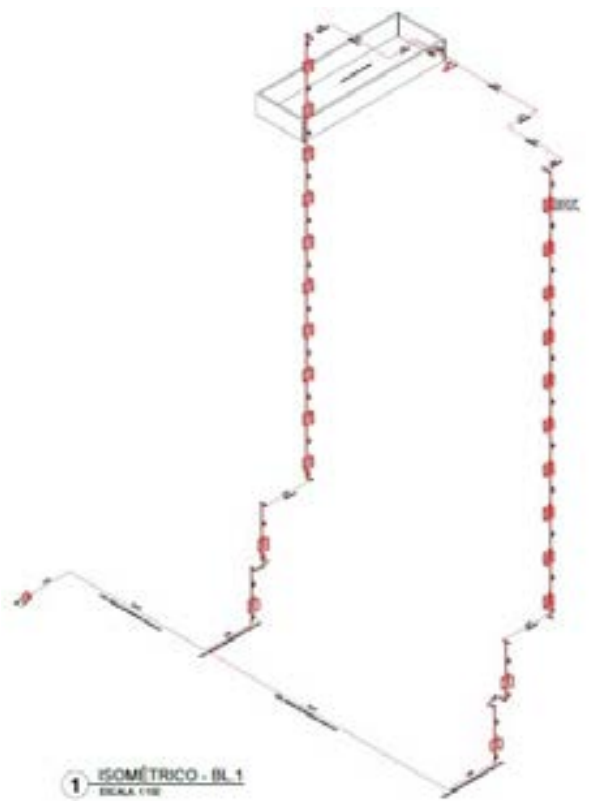

Fonte: (Projeto de Incêndio, 2017)

No projeto isométrico do sistema fixo preventivo é apresentado a localização do reservatório superior e sua capacidade em litros, a disposição da tubulação com suas medidas horizontais e verticais, a localização das caixas de incêndio, as curvas, o diâmetro da tubulação (que nesse caso é de $50 \mathrm{~mm}$ ou 2"), a forma que a tubulação passa quando chega ao patamar inferior, até finalizar no hidrante de recalque.

E de grande importância informar que nesse estudo de caso é possível apresentar duas peculiaridades que podem existir em sistemas preventivos de incêndio em relação a outros edifícios com características semelhantes. Como informado anteriormente nesse trabalho, edificações que antecedem a promulgação do COSCIP podem se eximir de algumas exigências. Nesse presente caso, podemos verificar que o edifício não possui 
o sistema de chuveiros automáticos (sprinklers) como também canalização fixa com diâmetro de $50 \mathrm{~mm}$ ou 2". Caso o mesmo edifício (que possui mais de $30 \mathrm{~m}$ de altura) fosse construído pós COSCIP, ele necessariamente possuiria o sistema de chuveiros automáticos como também sua tubulação seria de $2.1 / 2$ ".

Para maior compreensão das etapas de tramitação de projeto, vistoria e aprovação pelo Corpo de Bombeiros, será apresentado os dois principais documentos que o empreendimento deverá possuir e apresenta-los caso seja solicitado. Elucido que as imagens das documentações que seguem abaixo nas figuras 16 e 17, não são relativas às imagens do projeto de incêndio apresentado nas figuras 12, 13, 14, 15.

Figura 16 - Laudo de Exigências

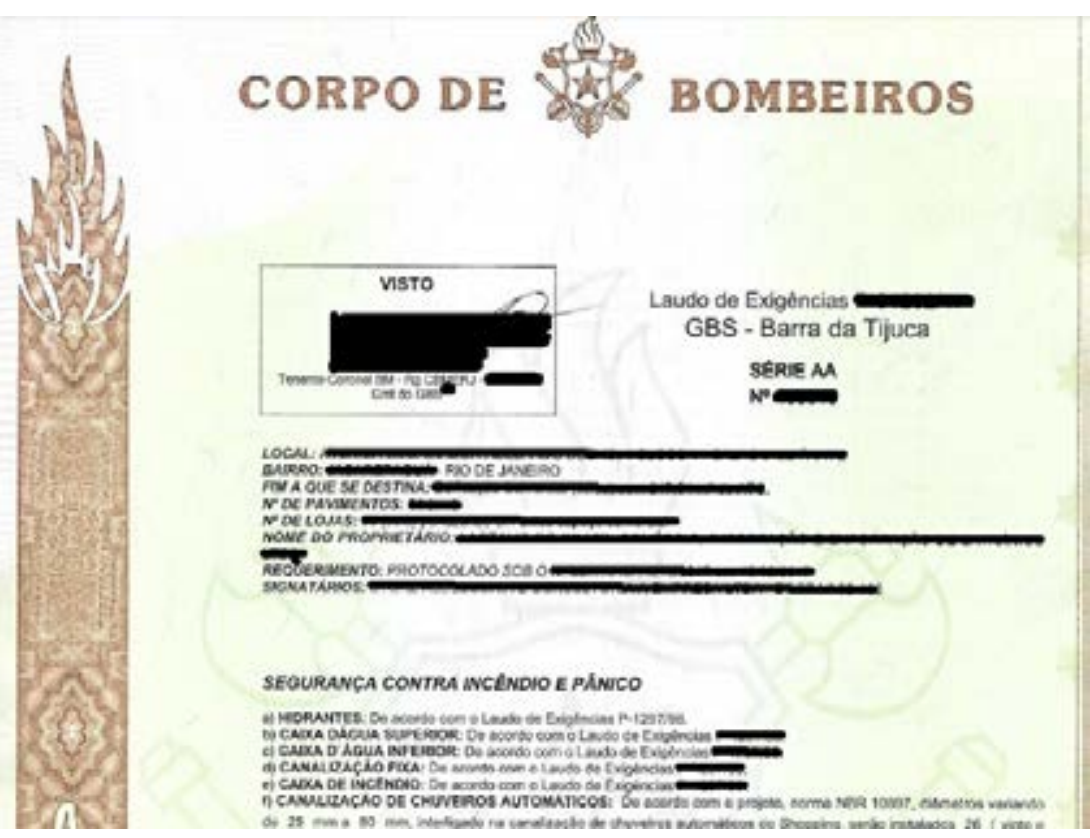

Fonte: (Laudo de Exigências - CBMRJ, 2017)

No Laudo de Exigências (figura 16) é informado o número do documento, local onde foi dado a entrada de tramitação, assinatura do profissional que realizou a aprovação do projeto de incêndio, empresa ou profissional autônomo que realizou o projeto contra incêndio, características do edifício e todos os detalhes quanto aos dispositivos que serão instalados no local e que serão avaliados na vistoria para a possível obtenção 
do Certificado de Aprovação. CERTIFICADO DE APROVAÇÃO (C.A.) - documento expedido através das SSCIP ou em casos especiais pela DST, certificando o cumprimento de todas as exigências contidas em Laudo de Exigências. (SEDEC Resolução 142, 94).

Certificado esse que segue na figura 17 de forma demonstrativa em imagem. Documento que deve permanecer em local visível no estabelecimento.

Figura 17 - Certificado de Aprovação

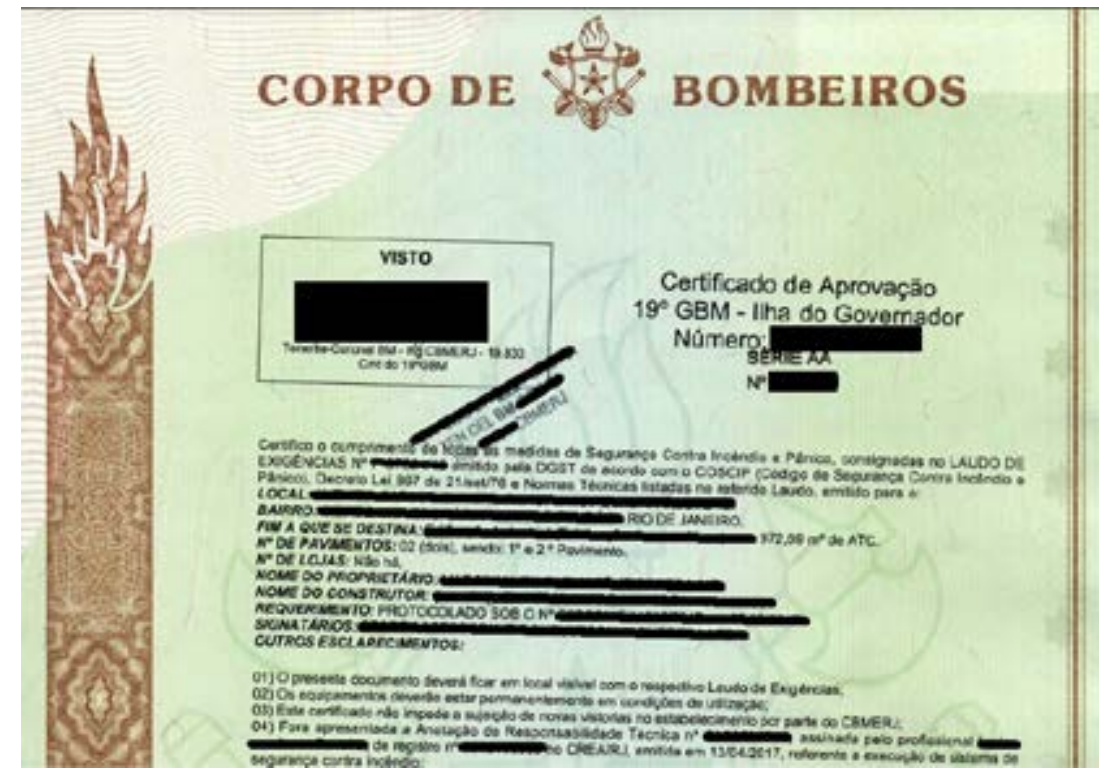

Fonte: (Certificado de Aprovação - CBMRJ, 2017)

\section{CONSIDERAÇÕES FINAIS}

Como foi visto nesse trabalho, existem variados tipos de dispositivos contra incêndio e suas exigências para execução. Mas ainda assim, nos dias atuais, em que existe vasta informação em torno do assunto, muitas edificações permanecem sem possuir sistemas contra incêndio conforme suas exigências. Outras até possuem, mas funcionam parcialmente ou sequer seriam acionados em caso de emergência. É comum verificar maior atenção aos aparelhos extintores, geralmente deixando os demais dispositivos de proteção fora de seu adequado funcionamento para uso. A manutenção pre- 
ventiva de todo o sistema de proteção deve ser praticada por seus responsáveis legais, realizando uma vistoria anual de todos os dispositivos. E como também de mesma importância, é a elaboração do projeto contra incêndio da edificação e sua aprovação pelo Corpo de Bombeiro. Dessa forma garantindo maiores chances de contenção ao princípio de incêndio, logo, evitando casos trágicos de perdas de vidas e materiais.

\section{REFERÊNCIAS}

ASSOCIAÇÃO BRASILEIRA DE NORMAS TÉCNICAS (ABNT). NBR 10897: Proteção contra incêndio por chuveiro automático. Rio de Janeiro, 2014.

NBR 11742: Porta corta fogo para saída de emergência. Rio de Janeiro, 2003.

. NBR 12693: Sistema de proteção por extintores de incêndio. Rio de Janeiro, 2010.

CBMES, Apostila Bombeiro Profissional Civil. Disponível em: < https://cb.es.gov.br/material-didatico > Acesso em: 10 out.2017.

CODIGO DE SEGURANÇA CONTRA INCÊNDIO E PÂNICO (COSCIP), Decreto № 897. Rio de Janeiro, setembro de 1976.

EMERGÊNCIA, Revista. Abril/2017. Disponível em: < http://www.revistaemergencia. com.br > Acesso em: 20 nov.2017.

EXCOMER, Sistema sprinkler contra incêndio. Disponível em: <http://www.excomer. com.br/siste ma-sprinkler-antincendio > Acesso em: 02 nov.2017.

HIDROVAR, Chuveiros automáticos. Disponível em: < https://www.hidrovar.com. br/categoria/ sprinkler-incendio > Acesso em: 17 out.2017. 
ITIU, Alexandre; ANTONIO, Afonso; DOMINGOS, Fabio; ONO, Rosaria; BENTO, Silvio; DEL CARLO, Ualfrido; PIGNATTA, Valdir. A Segurança Contra Incêndio no Brasil. PROJETO EDITORA. 2008.

RESOLUÇÕES SEDEC (SECRETARIA DE ESTADO DE DEFESA CIVIL). Normas Complementares ao Decreto no897 (COSCIP). № 169, Rio de Janeiro 1994.

. № 109. Rio de Janeiro, 1993.

№ 142. Rio de Janeiro 1994.

№ 300. Rio de janeiro 2006. 